International Journal of Osteoarchaeology

Int. J. Osteoarchaeol. 14: 457-474 (2004)

Published online 7 July 2004 in Wiley InterScience (www.interscience.wiley.com). DOI: 10.1002/oa.727

\title{
Seasonality only Works in Certain Parts of the Year: the Reconstruction of Fishing Seasons through Otolith Analysis
}

\author{
W. VAN NEER, ${ }^{a \star}$ A. ERVYNCK, ${ }^{b}$ L. J. BOLLE ${ }^{c}$ AND R. S. MILLNER ${ }^{d}$ \\ ${ }^{a}$ Royal Museum for Central Africa, Tervuren, Belgium and Katholieke Universiteit Leuven, \\ Laboratory of Comparitive Anatomy and Biodiversity, Leuven, Belgium \\ b Institute for the Archaeological Heritage of the Flemish Community, Phoenix Building, \\ Koning Albert II-laan 19 box 5, B-1210 Brussels, Belgium \\ c Netherlands Institute for Fisheries Research, Haringkade 1, Postbus 68, NL-1970 AB \\ ljmuiden, The Netherlands \\ 'Centre for Environment, Fisheries and Aquaculture Science, CEFAS Lowestoft Laboratory, \\ Pakefield Road, Lowestoft, Suffolk NR33 OHT, UK
}

ABSTRACT Seasonality estimations using incremental data usually suffer from small sample sizes and from the lack of comparison with sufficiently large modern samples. The present contribution reports on incremental studies carried out on large assemblages of plaice (Pleuronectes platessa) and haddock (Melanogrammus aeglefinus) from a late medieval fishing village (Raversijde, Belgium) on the North Sea coast. In an attempt to refine previous seasonality estimates made for this site, and to expand conclusions concerning general methodology, extensive monthly samples of modern otoliths of these species, caught within the North Sea, have also been investigated. The modern material shows that the timing of the seasonal changes in the edge type (hyaline or opaque) of the otoliths is extremely variable and that it is dependent on the fishing ground, the year considered, and the age of the fish. It also appears that the increase of the marginal increment thickness is highly variable, to such an extent that the thickness of the last increment of a single otolith is mostly useless for seasonality estimation. Where large archaeological otolith assemblages can be studied, preferably from single depositional events, seasonality determination becomes possible on the condition, however, that the archaeological assemblage corresponds to fish that were captured during their period of fast growth. The growth ring study on the otoliths from Raversijde shows that plaice fishing took place in spring and that it was preceded by a haddock fishing season, probably in late winter/early spring. Copyright @ 2004 John Wiley \& Sons, Ltd.

Key words: incremental growth; seasonality; Pleuronectes platessa; Melanogrammus aeglefinus; archaeozoology

\section{Introduction}

For more than half a century, wildlife and fishery services have established ageing methods using the hard tissues of fish (e.g. Le Cren, 1947; Marzolf, 1955; Watson, 1964), birds (e.g. Klevezal

\footnotetext{
* Correspondence to: Royal Museum for Central Africa, Leuvensesteenweg 13, B-3080 Tervuren, Belgium.

e-mail: vanneer@africamuseum.be
}

et al., 1972; Stone \& Morris, 1981) and mammals (e.g. Morris, 1972) in order to gain insight in the age structure of populations. For mammals, tooth replacement and tooth wear were used initially (e.g. Matschke, 1967; Laws, 1968; Habermehl, 1985), but later on cementum layer counts were introduced (e.g. Laws, 1952; Klevezal \& Kleinenberg, 1967; Keiss, 1969). It was precisely the extrapolation, from the available wildlife literature, of this more refined analysis of 
incremental structures that allowed the establishment of the age at death of an animal within archaeozoological studies on the basis of dental material (e.g. Stallibrass, 1982). Starting from the assumption of fixed reproductive seasons for the species investigated, it consequently became possible to investigate seasonal killing on the basis of the detailed age at death estimations. For such assessment of seasonality in archaeozoological material, however, the methods used in wildlife studies needed to be refined. In archaeozoological seasonality studies using incremental structures, most attention has been paid to mammals (e.g. Bourque et al., 1978; Lieberman, 1994; Lieberman \& Meadow, 1992; Lubinski, 2001) and molluscs (e.g. Ham \& Irvine, 1975; Koike, 1975; Milner, 2001), whereas fish (see below) have received less attention, thus hampering the full exploration of the seasonality issue. Moreover, it has proven to be vital that sufficiently large modern samples are used of the species under study, in order to document the increment changes throughout the year (cf. Monks \& Johnston, 1993: 31), a methodological step that was only rarely taken in the past (e.g. for molluscs, Gaillard \& Testud, 1980; Claessen, 1993). However, seasonality studies do now increasingly concentrate on the analysis of modern control samples (e.g. Burke \& Castanet, 1995; McKinley \& Burke, 2000; Weinand, 2000; Whittaker \& Enloe, 2000; Lubinski \& O'Brien, 2001).

In fish, incremental studies have been carried out on vertebrae (e.g. Desse, 1983; NoeNygaard, 1983; Desse \& Desse-Berset, 1993), fin spines (Brewer, 1987; Van Neer, 1993) and otoliths (Smith, 1983; Carlson, 1988; Hales \& Reitz, 1992; Van Neer et al., 1993; Higham \& Horn, 2000). As in mammals, it is evident that the information yielded by modern population studies was limited to the timing of annulus formation, since fishery studies are primarily interested in age profiles of populations and growth rates. The majority of the archaeozoological seasonality studies in fish mentioned above used the edge type of the analysed structure and gave a rather subjective measure of the amount of marginal increment available (compared to the expected total increment width). The gradual increase in the marginal increment throughout the year has not been studied in detail, except in a few cases

Copyright (C) 2004 John Wiley \& Sons, Ltd.
(Carlson, 1988). The latter author offered much criticism against the methodology used thus far and concluded that growth ring analysis of vertebrae and otoliths is unreliable for seasonality determination. Not all authors, however, agreed with this view (see Desse \& Desse-Berset, 1992).

Otoliths grow by the deposition of aragonite, a form of calcium carbonate that is deposited on an organic matrix. The appearance of the aragonite changes during the year, depending on environmental conditions such as food (Alhoussaini \& Pitcher, 1988) or temperature (e.g., Brothers, 1981; Mosegaard et al., 1988). In general, however, during periods of rapid growth the otolith forms an opaque zone while in periods of reduced growth the otolith has a more hyaline (or translucent) appearance. Seasonal changes in the otolith structure vary geographically, but in a review (Beckman \& Wilson, 1995) the dominant period for opaque formation was demonstrated to fall in spring and summer in both northern and southern hemispheres.

The present study investigates possible seasonal fishing for two species, i.e. plaice (Pleuronectes platessa) and haddock (Melanogrammus aeglefinus), at an archaeological site, on the basis of the excavated otoliths. In order to interpret the edge type on the archaeological otolith samples, the timing and appearance of edge types were first investigated on recent otoliths from both species. In addition, the monthly increase of the marginal increment was studied in modern material. On the basis of these recent observations, and the archaeological test-case, it was evaluated what the possibilities are for establishing the season of catch for different types of archaeological assemblages, i.e. a single otolith, an assemblage of specimens derived from a single event (a single catch), and an assemblage of specimens from deposition over a longer period.

\section{Material and methods}

Plaice and haddock, as North Sea species, are still of great economic importance, hence abundant data could be gathered from the fishery biology literature. During a EU-funded project involving partners from fishery institutes in The Netherlands, England and Belgium, large samples of modern 


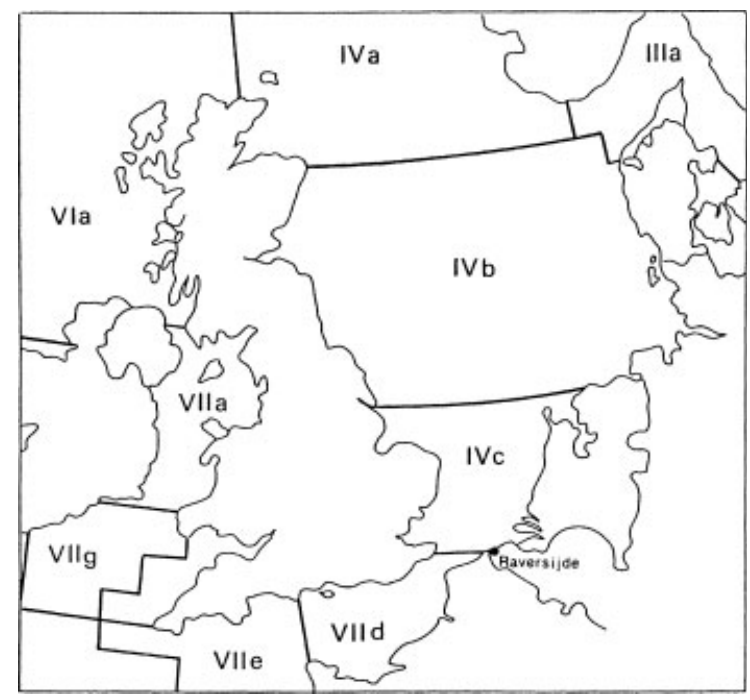

Figure 1. The ICES divisions of the North Sea from which modern otoliths were studied and the location of the archaeological site Raversijde.

Table 1. Number of modern otoliths analysed for edge type, excluding specimens where edge type was unclear (sampling year 1996)

\begin{tabular}{lccc}
\hline Month & $\begin{array}{c}\text { Plaice } \\
\text { Central North } \\
\text { Sea (IVb) }\end{array}$ & $\begin{array}{c}\text { Plaice } \\
\text { Eastern English } \\
\text { Channel (VIld) }\end{array}$ & $\begin{array}{c}\text { Haddock } \\
\text { Central North } \\
\text { Sea (IVb) }\end{array}$ \\
\hline Jan & 196 & 134 & 91 \\
Feb & 245 & 138 & 109 \\
Mar & 233 & 126 & 101 \\
Apr & 184 & 167 & 106 \\
May & 325 & 151 & 111 \\
Jun & 194 & 141 & 98 \\
Jul & 237 & 156 & 117 \\
Aug & 269 & 159 & 110 \\
Sep & 176 & 161 & 94 \\
Oct & 285 & 215 & 120 \\
Nov & 212 & 176 & 126 \\
Dec & 161 & 154 & 114 \\
Total & 2717 & 1878 & 1297 \\
\hline
\end{tabular}

otoliths from different parts of the North Sea (Figure 1) could be analysed that formed a valuable database against which the archaeological otoliths could be studied. In a total of 4595 modern plaice otoliths and 1297 haddock otoliths the edge type (hyaline or opaque) was identified (Table 1). For the analysis of the modern increment widths, a subsample comprising 387 plaice was studied. This material, together with other medieval and post-medieval assemblages and further recent otoliths, has already been used in a study of the diachronic changes in growth rate related to fishing pressure (Van Neer et al., 2002).

The archaeological material came from the former fishermen's village of Raversijde, located west of Oostende, along the Flemish coast (Figure 1). Rescue excavations at the site have uncovered mainly structural remains and refuse deposits dating from the 15 th century AD (Pieters, 1997). Analysis of the fish remains from the site, and the available historical information, has shown that the late medieval fishermen visited fishing grounds in the North Sea, off the English and Scottish coasts, concentrating on the catch of herring and gadids. Flatfish, especially plaice, were also an important product but these species were probably caught in more local coastal waters, off the Flemish coast (Pieters et al., 1994; 1996; Ervynck et al., in press). Within the present study, otoliths were used that were collected from sieved samples from a wide variety of archaeological contexts (ditches, refuse dumps, etc.). However, one special context (hereafter called 'the pit') was treated separately: a refuse pit containing the bones from the heads and tails of several hundred individuals of plaice, without doubt the leftovers of the processing of a single catch (Van Neer \& Pieters, 1997). In total, 119 plaice otoliths were sectioned from the pit and 279 specimens from the other contexts of the site. In addition 202 haddock otoliths from various contexts at Raversijde were analysed. A single event deposition of haddock remains was not available from the site.

In a previous study (Van Neer et al., 1999) 50 plaice otoliths from the pit at Raversijde were analysed, but the procedures were different compared to those used within the present study: growth lines were observed on complete specimens and on a subsample of broken and burned otoliths. This previous study lacked comparison with modern reference material. In this study both archaeological and modern material was involved, and sections were used because much of the recent material available for haddock and plaice was in the form of thin sections.

The preparation of the thin sections of both the recent and the archaeological material followed the procedures described by Bedford (1983). Otoliths were embedded in black polyester resin and transverse sections of $0.4-0.5 \mathrm{~mm}$ thick were 
cut through the centre, exposing the nucleus and the annual ring structure. Although the transverse plane, which bisects the anterior-posterior axis of the otolith, produces the most compressed crosssection with the least surface area and smallest distance between sequential growth structures, it is generally the easiest and most accurate method of capturing the full growth history from larval nucleus to the edge (Mosegaard et al., 1998). The otolith images were digitized using a microscope and a digital camera. The edge type of each sectioned otolith was identified and the incremental measurements were taken from digital images of the sectioned otoliths using image analysis software. The greatest width of the otolith and the X-Y coordinates of the hyalineopaque transition were recorded at the outermost tips of each annulus, after which these X-Y measurements were converted to annulus diameter. However, the direction of otolith growth changes with age from a posterior-anterior direction (increase in otolith width) to a dorso-ventral direction (increase in otolith thickness), as illustrated for a plaice otolith in Figure 2. The annulus diameter was thus calculated for the main axis of growth, which is defined as the greatest width axis. Therefore, the X-Y coordinates of the tips of each annulus were projected on the main axis of growth (A-A in Figure 2). The distance between the projected tips of annulus $i$ is the otolith diameter at age i. The obtained measurements were then used to calculate annual growth increments. The increment following the last completed annulus is referred to as the marginal increment.
The results obtained will be described in two parts following the two basic approaches: identification of the edge type (opaque or hyaline) and measurement of the marginal increment. The numerous observations made on the modern material will always be discussed first, followed thereafter by presentation of the results obtained from the archaeological material.

\section{The edge type of the otolith}

\section{Plaice}

Based on a previous growth study (Rijnsdorp et al., 1990) it is concluded that the transition from hyaline to opaque on average corresponds to the 1st April and that the growing season ends on the 30th October. From the monthly analysis of the recent otoliths it is now clear that this pattern is not clear-cut and that large variation in growth patterns must exist between individuals. Figure 3 shows that during almost all months of the year opaque and hyaline otoliths can be found within the plaice population, be it in different frequencies.

The first conclusion from the recording of the recent plaice otoliths must thus be that the edge type (hyaline or opaque) of a single archaeological otolith will always be insufficient to determine the season of capture of an individual fish, because each edge type can be found throughout most of the months within a year. Of course the probabilities of finding a certain edge type are different for each month, but

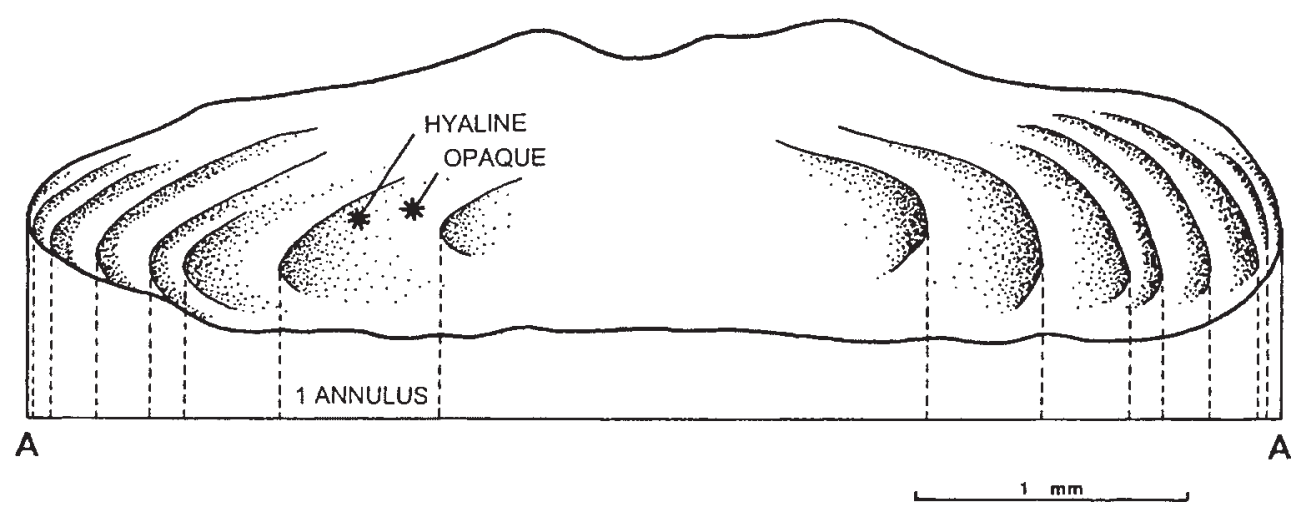

Figure 2. Schematic thin section of a plaice otolith with indication of the measured increments.

Copyright (C) 2004 John Wiley \& Sons, Ltd.

Int. J. Osteoarchaeol. 14: 457-474 (2004) 

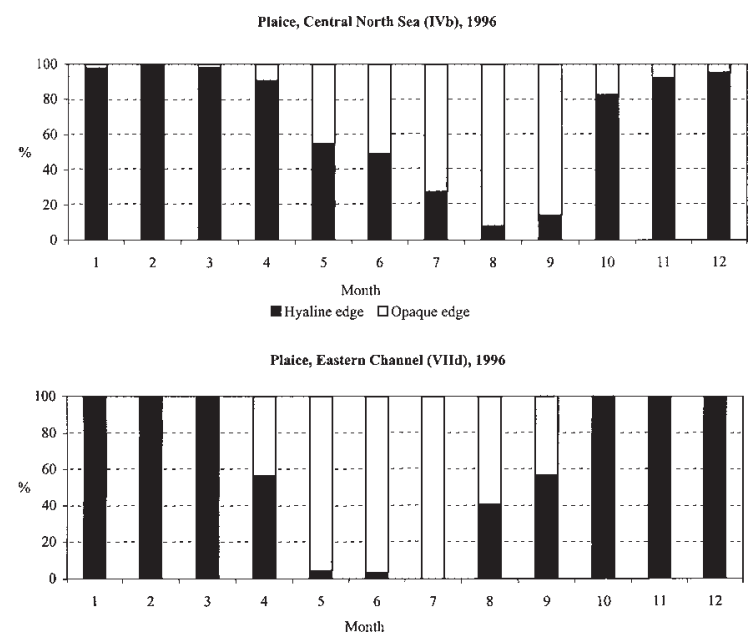

Figure 3. The seasonal change in percentage edge type from hyaline to opaque for modern plaice from the central North Sea (IVb) and the eastern Channel ( VIId) in 1996.

complete certainty will never be achieved. This would only be possible in the case of a 100\% occurrence of a type within a certain month, a condition that is seldom observed in fish populations today.

When dealing with an assemblage of archaeological otoliths from one context or a variety of contexts within a site, possibly representing a long period or multiple depositions, the use of the $\mathrm{H} / \mathrm{O}$ (hyaline/opaque) ratios has equally low probability of being successful. A given ratio within such an archaeological assemblage can never be explained in an unequivocal way, since, even when the deposit dates from a single year, the ratio observed can be the reflection of a single short fishing season or can be an average of unknown amounts of fish captured at different periods within that year. When the assemblage investigated was deposited during several different years, the situation becomes even more complex. However, when dealing with an assemblage of archaeological otoliths that represents a single depositional event, the $\mathrm{H} / \mathrm{O}$ ratio could be of use. Even then, large samples will be needed, so that the effects of individual variation are tempered, but the ratio could then be significant and may in some cases indicate a particular fishing season. However, since growth is a cyclic phenomenon, comparable frequencies of hyaline versus opaque are found to occur in very different months, for example in April and November of

Copyright (C) 2004 John Wiley \& Sons, Ltd.
1996 for plaice from the central North Sea (Figure 3).

There are even more complicating factors hampering the evaluation of all types of archaeological assemblages. The data indicate that the timing of deposition of opaque material is dependent on the area where the fish come from and on the age of the individuals considered. Figure 3 shows the percentage of opaque and hyaline edges observed for each month of 1996 for plaice from the central North Sea and from the eastern Channel. It appears that the development of a new opaque zone on the edge of the otolith started in April (9\% of the central North Sea plaice and $43 \%$ of the English Channel had an opaque edge). By May, nearly all otoliths examined in the eastern Channel had an opaque edge and the opaque zone continued to develop on the edge for the next 3 months. By contrast, in the central North Sea there was a steady increase in the proportion of opaque edges, but a significant percentage of the individuals retained a hyaline edge throughout June and July. The switch to hyaline growth also started earlier in the eastern Channel: around $40 \%$ of the fish had hyaline material on the edge in August compared to about $10 \%$ in the central North Sea. In both areas, the majority of otoliths (82-100\%) had a hyaline edge in the period from October to March.

The differences in growth of plaice in the eastern Channel and the central North Sea are thought to be largely due to temperature differences between the two areas. Temperatures in the shallow eastern Channel (and the southern North Sea, for which we do not have sufficient samples) increase rapidly in May and June and reach a higher average temperature between July and September than is the case in the deeper waters of the central North Sea. Average temperatures in the southern Bight reach $16^{\circ} \mathrm{C}$ whereas north of $56^{\circ} \mathrm{N}$ temperatures remain between $6^{\circ} \mathrm{C}$ and $10^{\circ} \mathrm{C}$. Opaque material is thought to be deposited during periods of high food availability and low temperatures (Mosegaard et al., 1988). The change to hyaline deposition is thus probably a response to a decrease in food in late summer while sea temperatures remain high. Measurable growth ceases in October or November and the hyaline edge remains until new growth starts the following spring.

Int. J. Osteoarchaeol. 14: 457-474 (2004) 
Table 2. Monthly percentage of opaque edges observed in modern samples of central North Sea (IVb) plaice in the years 1995 and 1996

\begin{tabular}{lrr}
\hline Month & 1995 & 1996 \\
\hline 1 & 0.0 & 2.0 \\
2 & 0.0 & 0.0 \\
3 & 2.3 & 1.7 \\
4 & 32.8 & 9.2 \\
5 & 61.6 & 44.9 \\
6 & 74.2 & 50.5 \\
7 & 88.3 & 72.2 \\
8 & 95.6 & 91.8 \\
9 & 59.7 & 85.8 \\
10 & 18.6 & 17.5 \\
11 & 8.3 & 8.0 \\
12 & 0.6 & 5.0 \\
\hline
\end{tabular}

The seasonal changes in edge type are not only depending on the area, but can also differ from one year to the other, as shown by the data from 1995 and 1996 (Table 2). Without doubt, such variations also occurred in the past. Another factor that needs to be taken into account is the fact that younger fish start growth earlier in the year than older animals. Figure 4 compares the growth rates for North Sea and eastern Channel plaice at 3 and 6 years. In the eastern Channel, $60 \%$ of the 3 -year-old individuals had an opaque edge in April whereas only $20 \%$ of the 6 -year-olds had started to form opaque material.
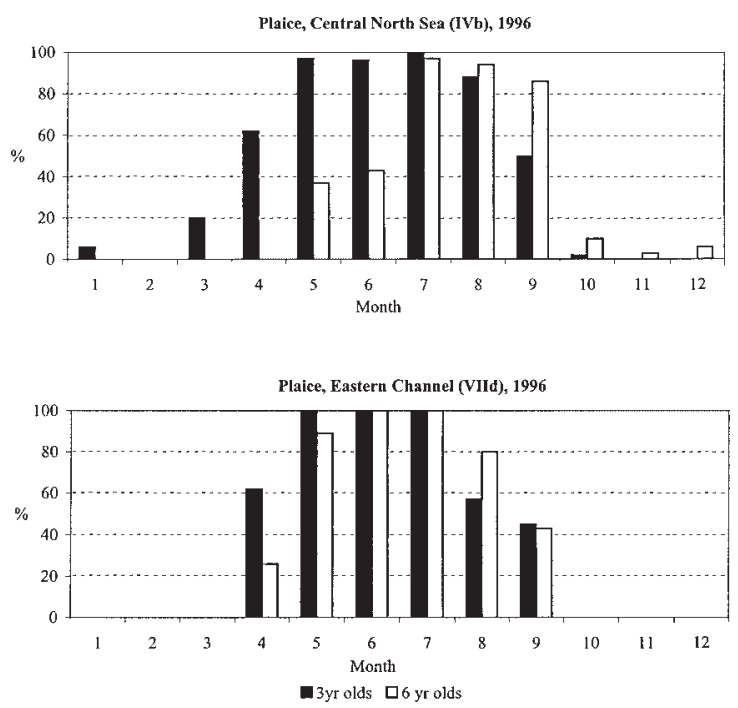

Figure 4. Percentage of otoliths with opaque edge at age 3 and 6 in the central North Sea and the eastern Channel.

Copyright (C) 2004 John Wiley \& Sons, Ltd.
The difference was even more marked in the North Sea where 20\% of the 3-year-olds had an opaque zone on the edge in March and nearly $100 \%$ in May. The 6-year-olds, however, were slower to start growth: there was no evidence of opaque material in April and only 40\% had formed opaque material on the edge in May.

From the above, it follows that it can only be profitable to work with assemblages of several otoliths found in archaeological layers instead of considering each otolith individually. However, as has been explained, it is obvious that a mere comparison of the $\mathrm{H} / \mathrm{O}$ ratios from archaeological sites to the ratios available from the modern specimens (Figures 3 and 4) cannot yield much relevant information concerning the season of capture, except in cases where there is archaeological evidence that the deposit was formed within a relatively short period (and even then confusion between months can occur, see above). Moreover, it must not be forgotten that the aforementioned modern data show that growth differences exist between various fishing grounds and different age groups, and that interannual variations also occur. Of the analysed archaeological otoliths only the plaice specimens from the pit at Raversijde can be considered to represent a single depositional event. All the other contexts from the site contain fish remains that may have been deposited over a long period within the year and this for several years or decades in a row. The latter contexts can represent a mixture of fishes that were captured over several months but since the exact length of the fishing season is unknown and since it cannot be established what the monthly amount of captured fish was, it is impossible to reconstruct an average $\mathrm{H} / \mathrm{O}$ ratio that can be expected in a particular period of the year. Thus, only crude seasonality estimates may be conducted using the $\mathrm{H} / \mathrm{O}$ ratio and they will always be rather unreliable. If an archaeological context yielded plaice otoliths that exhibit exclusively hyaline edges, it could be assumed that fishing took place in winter (although hyaline specimens occur throughout the year). Similarly, a $100 \%$ frequency of opaque edges would be typical of summer fishing (although this edge type occurs from spring to autumn). Clearly, even more interpretation problems will occur when both edge types are present.

Int. J. Osteoarchaeol. 14: 457-474 (2004) 
Table 3. Percentage of opaque edges observed in modern samples (sampling year 1996) of plaice from different zones and in different age classes (number of specimens in parentheses)

\begin{tabular}{|c|c|c|c|c|c|c|}
\hline \multirow[t]{2}{*}{ Month } & \multicolumn{3}{|c|}{ Central North Sea (IVb) } & \multicolumn{3}{|c|}{ Eastern English Channel (VIId) } \\
\hline & All ages $(n=2717)$ & Age $3(n=237)$ & Age $6(n=272)$ & All ages $(n=1878)$ & Age $3(n=317)$ & Age $6(n=171)$ \\
\hline 1 & 2 & 6 & 0 & 0 & 0 & 0 \\
\hline 2 & 0 & 0 & 0 & 0 & 0 & 0 \\
\hline 3 & 2 & 20 & 0 & 0 & 0 & 0 \\
\hline 4 & 9 & 62 & 0 & 43 & 62 & 26 \\
\hline 5 & 45 & 97 & 37 & 95 & 100 & 89 \\
\hline 6 & 51 & 96 & 43 & 96 & 100 & 100 \\
\hline 7 & 72 & 100 & 97 & 100 & 100 & 100 \\
\hline 8 & 92 & 88 & 94 & 59 & 57 & 80 \\
\hline 9 & 86 & 50 & 86 & 43 & 45 & 43 \\
\hline 10 & 18 & 2 & 10 & 0 & 0 & 0 \\
\hline 11 & 8 & 0 & 3 & 0 & 0 & 0 \\
\hline 12 & 5 & 0 & 6 & 0 & 0 & 0 \\
\hline
\end{tabular}

Of the 279 otoliths recovered from a variety of contexts at Raversijde, $43 \%$ have an opaque edge. Not surprisingly, this ratio is difficult to interpret. It corresponds to what has been found in the modern specimens from the English Channel in April and September, and it also corresponds to the values observed for the months of May and June in the central North Sea (Table 3). However, this ratio can also be attained in various other ways, e.g. by assuming that fishing started in winter when most edges were hyaline and continuing into spring and early summer when opaque material was laid down. Moreover, the exploitation of various fishing grounds, different age groups and interannual variations can have had their effect.

In the case of the single depositional context from the Raversijde pit, these drawbacks do not have to be taken into account. Of the 119 otoliths from the pit, 95\% have an opaque edge. This ratio corresponds well to the August value for the central North Sea and to the May and June values for the English Channel (see Table 3 and Figure 3 ). Starting from the $\mathrm{H} / \mathrm{O}$ ratio, it thus appears that plaice from the Raversijde pit were captured in late spring or summer. If these fish were from the central North Sea, then the seasonality estimate is certainly in contradiction with the season expected from historical sources (Egmond, 1997) and also with the isotope data derived from plaice otoliths from the same context (Patterson 2000; Patterson et al., in preparation), both indicating plaice fishing during spring (see discussion

Copyright (C) 2004 John Wiley \& Sons, Ltd. below). However, if they were caught off the Belgian coast, then the fish would be expected to show growth patterns more similar to the English Channel sample. This would suggest that the fish were taken in a late spring fishery, which is still later than indicated by the historical sources. The possible role of a different age composition of modern and historical samples also needs to be taken into account. The historical material comprises mainly relatively young specimens (see age distribution curve in Figure 5) compared to the modern samples, animals for which the growth would have started earlier in the season. However, the seasonality estimate remains the same when the 3 and 6 year classes of the Raversijde pit are analysed separately and compared to the data in Table 3: $100 \%$ opaque edges $(n=11)$ for the 3 year class and $93 \%$ for the 6 year class $(n=29)$. An interpretation problem thus remains.

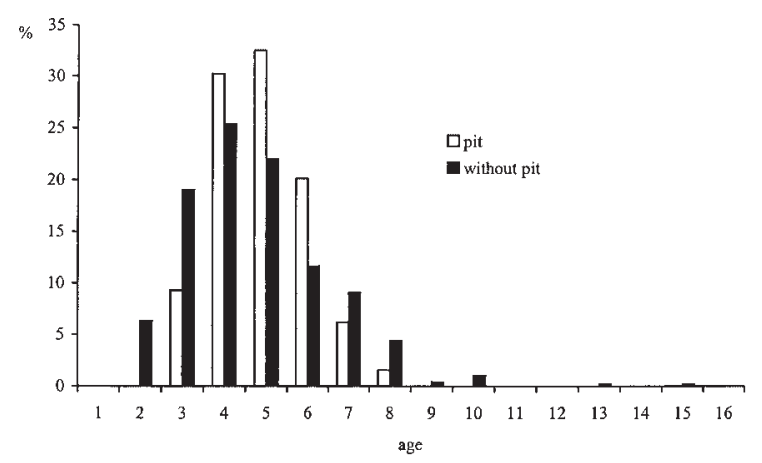

Figure 5. Age distribution of plaice from Raversijde in the pit $(n=129)$ and in all the other contexts $(n=472)$.

Int. J. Osteoarchaeol. 14: 457-474 (2004) 


\section{Haddock}

The distribution of haddock has varied over time and the species was more abundant in the North Sea at the beginning of the 19th century than today (Rijnsdorp et al., 1996). Nowadays, the species is absent from the southern North Sea, but historical data show that it was abundant in late medieval times (Egmond, 1997). It is obvious that this lack of modern otolith collections from this area will hamper comparisons with the archaeological material.

The data considered regarding the growth of modern haddock are from populations from the central North Sea sampled in 1996. It appears that, in that year, growth in modern haddock from the central North Sea remained at a low level until May, with only $10 \%$ of samples showing an opaque edge type (Figure 6). About 60\% of haddock had developed an opaque edge in June and all samples showed opaque edges in August. The start of hyaline growth appears to have been delayed until September and around $10 \%$ of haddock samples continued to show an opaque zone until December.

Extrapolating the observational results of the modern plaice otoliths, it is conceivable that the presence of different age groups, various fishing grounds and interannual variation will also be factors that must be taken into account. However, detailed data to evaluate these factors are not available, especially because haddock no longer occurs in the southern North Sea. It is likely that the haddock populations formerly living in the southern North Sea will have started the deposition of opaque material earlier than

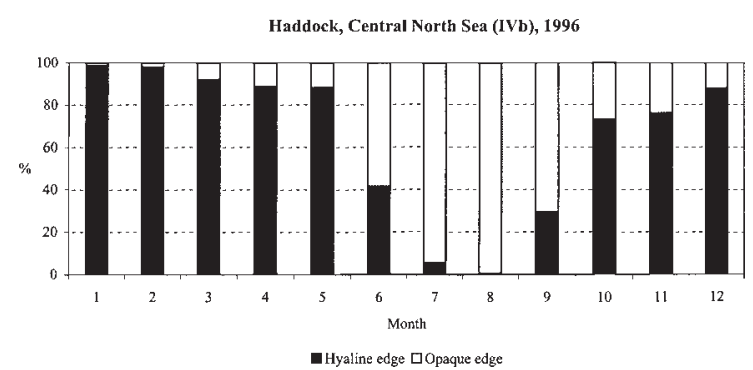

Figure 6. The seasonal change in percentage edge type from hyaline to opaque for modern haddock from the central North Sea (IVb) in 1996.

Copyright (C) 2004 John Wiley \& Sons, Ltd.
Table 4. Edge type of haddock otoliths from Raversijde

\begin{tabular}{lcc}
\hline Edge type & Number & $\%$ \\
\hline $\mathrm{H}$ & 28 & 14.4 \\
$\mathrm{H} / \mathrm{O}$ & 82 & 42.3 \\
$\mathrm{O}$ & 49 & 25.3 \\
O- & 35 & 18.0 \\
Total & 194 & 100 \\
\hline
\end{tabular}

$\mathrm{H}$, hyaline; $\mathrm{H} / \mathrm{O}$, hyaline on one side, opaque at the other; $\mathrm{O}$, opaque; O-, narrow opaque.

those from the central North Sea, but there are no recent data to corroborate this.

The observation of the edge type in haddock otoliths from Raversijde was less straightforward than for plaice. Aside from otoliths that had a clear opaque or hyaline edge, there were specimens that showed a hyaline edge at one side of the thin section and a very narrow opaque increment at the other side (indicated as $\mathrm{H} / \mathrm{O}$ in Table 4). The latter specimens were from individuals that were clearly at the end of their slow growing season and in which the new growth was starting. Among haddock from Raversijde, 14\% had a hyaline edge at their complete periphery, but when those otoliths are added that have such an edge type on one side the ratio becomes 57\% hyaline edges. This $\mathrm{H} / \mathrm{O}$ ratio observed in the Raversijde haddock would correspond to what can be expected in the central North Sea today in May-June or September-October. As mentioned earlier, however, a fishing season early in spring can be postulated for the late medieval haddock populations of the southern North Sea. Of course, other restrictions in the interpretation also occur, similar to those mentioned for plaice. The haddock assemblage from Raversijde has been collected from a variety of contexts and therefore does not represent a single catch. Haddock fishing is likely to have extended over several months and the ratio observed could have been obtained in various ways.

\section{The marginal increment width}

Plaice

As the ratio of opaque versus hyaline edges is a very crude measure in seasonality estimates,

Int. J. Osteoarchaeol. 14: 457-474 (2004) 

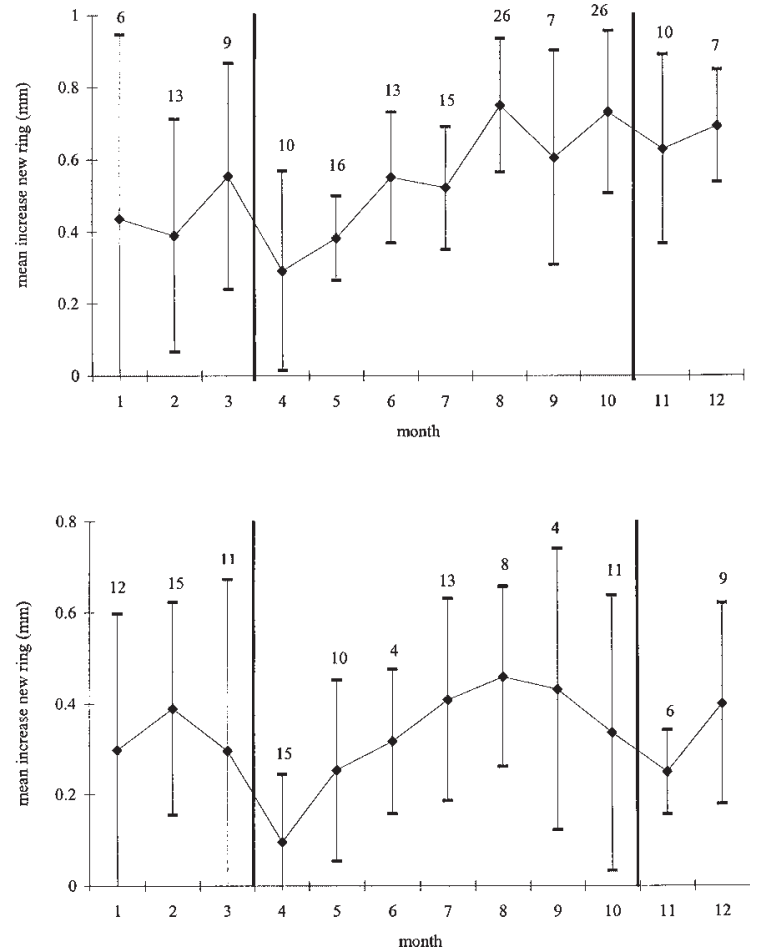

Figure 7. Monthly mean increase (and \pm one standard deviation) of the marginal increment for the third ring (upper panel) and fourth ring (bottom panel) of modern plaice. The solid vertical lines indicate the beginning and the end of the growing season as it is usually defined for plaice (start 1st April, end 30th October). The number of specimens in each monthly sample is indicated.

the width of the marginal increment must now be taken into account in an attempt to use the monthly otolith samples of modern specimens as a reference to predict the season of capture of the archaeological specimens. Figure 7 shows the monthly mean width of the marginal increment for the third and fourth ring of modern plaice. From April onwards, the postulated start of the growth season, a clear and steady increase of the increment is visible, which reaches a plateau in July-August. It is, however, also evident from the standard deviations that there is an enormous variation within each month, and, consequently, a very large overlap between months. This large variation, being the result of variation in growth itself combined with the variation observed in the appearance of the opaque and hyaline zones (early or late growth start), severely reduces the accuracy of any seasonality determinations following this approach. In the case of a single archaeological otolith, it will appear that the marginal increment measurement corresponds to practically all months of the year within the recent data set (Figure 7 ). Even when dealing with material of many individuals from a single depositional event, such as the pit at Raversijde, problems remain with this approach. Even then, the average marginal increment and the standard deviation will not necessarily be conclusive. Figure 7 (bottom panel) shows, for instance, that the same variation is seen in the months of February, July and December. When dealing with an assemblage of archaeological otoliths from one context or a variety of contexts within a site, possibly representing a long period or multiple depositions, the mean and variation observed will be even more difficult to interpret.

It is possible that enlarging the modern otolith sample may improve the reference curve, but it is unlikely that the standard deviations will decrease sufficiently to make this approach a successful application. An additional drawback of the method is that the modern samples do not necessarily show the same growth pattern as the historic ones. Table 5 shows that there is a difference between the modern and archaeological samples in the mean width attained at various ages. The modern, overexploited, populations of plaice grow more rapidly than the late medieval ones (see also Van Neer et al., 2002), and, as a result, the growth increments are larger in the modern material. This potential source of bias has to be added to the variation expected from the fact that growth can start at a different moment depending on the fishing area, that growth is agedependent with younger fish starting their growth earlier in the year, and that growth will vary between years. Reference curves should thus be made for different age classes, from

Table 5. Mean width in $\mathrm{mm}$ of plaice otoliths at various ages from the modern and archaeological samples

\begin{tabular}{lcc}
\hline Ring & Modern & Raversijde \\
\hline 3 & 3.85 & 3.24 \\
4 & 4.23 & 3.80 \\
5 & 4.44 & 4.13 \\
6 & 4.59 & 4.33 \\
7 & 4.84 & 4.56 \\
8 & 5.05 & 4.86 \\
9 & 5.39 & 5.40 \\
\hline
\end{tabular}

Int. J. Osteoarchaeol. 14: 457-474 (2004) 
different areas within the North Sea and for many different years. Constructing a curve based on archaeological otoliths is, of course, impossible since the capture date of the specimens is unknown. However, as will be shown below, observing the archaeological material is useful for the analysis of the full widths that can be attained by each individual full increment.

An alternative approach is to express the observed marginal increments as a function of another measurement from the same otolith sample. This could reduce the variation linked with many of the factors described above. Monks \& Johnston (1993), in a theoretical overview of possible methods for seasonality estimations from growth increments, concluded that sophisticated methods are not very rewarding. They postulated that good results could be obtained by comparing the width of the marginal increment to the width of the preceding full growth zone, a method that has already been applied to another sample of plaice otoliths from Raversijde, where each marginal growth increment was expressed as a percentage of the preceding increment (Van Neer et al., 1999). However, the relation between the widths of successive growth zones has been examined for plaice from Raversijde (Figure 8)
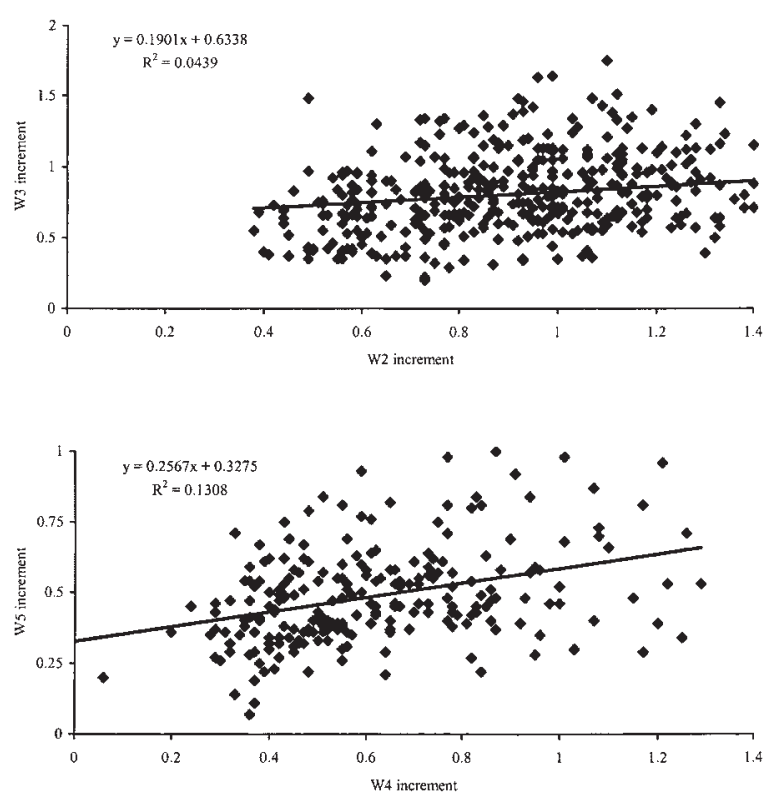

Figure 8. Relation between width (in $\mathrm{mm}$ ) of second and third increment (upper panel), and between fourth and fifth increment (lower panel) of plaice from Raversijde.

Copyright (C) 2004 John Wiley \& Sons, Ltd. and it is obvious that there is no significant correlation, possibly as a result of individual and interannual variation in growth. This explains the results that were obtained previously (Van Neer et al., 1999: Figure 5) whereby complete rings had a width of between $40 \%$ and $150 \%$ of the previous ring!

Since working with relative widths (which, in the case of plaice, are not based on significant regressions) involves more calculations and introduces uncertainties, it is preferable to work with absolute values. First, the distribution of the marginal increments at a certain age can be analysed. When dealing with an assemblage deposited over several years, a unimodal distribution of the marginal increments could occur if a single fishing season existed, although interannual and geographic variations are likely to blur the picture. In the case of a single depositional event, thus an assemblage of fish captured at the same time, a unimodal distribution is expected, possibly showing less variation than in the case of a multiple or longer depositional event. When dealing with otoliths from an assemblage corresponding with fish deposited at different seasons or over a long period of the year (or successive years), several peaks in the distribution can be expected (in the clearest case), although in most instances a more blurred picture will occur. In theory, the form of the distribution could thus reveal whether we are dealing with a seasonal phenomenon or not. As a second step, and in the case of a unimodal distribution of marginal increments, it is possible to compare the position of the mean or modus with that of the distribution of complete increments for the same full growth ring (to be observed from all specimens from the same assemblage that are at least 1 year older).

The distribution of the marginal widths of plaice from the pit at Raversijde, which correspond to a single catch, is shown in Figure 9 and compared to the expected mean thickness of the complete increment calculated from individuals from the same site (arrowed in Figure 9). Except for the fourth ring, for which the sample size is rather small, the distribution of the marginal increments resembles a unimodal distribution, as expected. Moreover, compared to the arrows that indicate the mean increment of complete rings, the peaks are situated towards the left part

Int. J. Osteoarchaeol. 14: 457-474 (2004) 

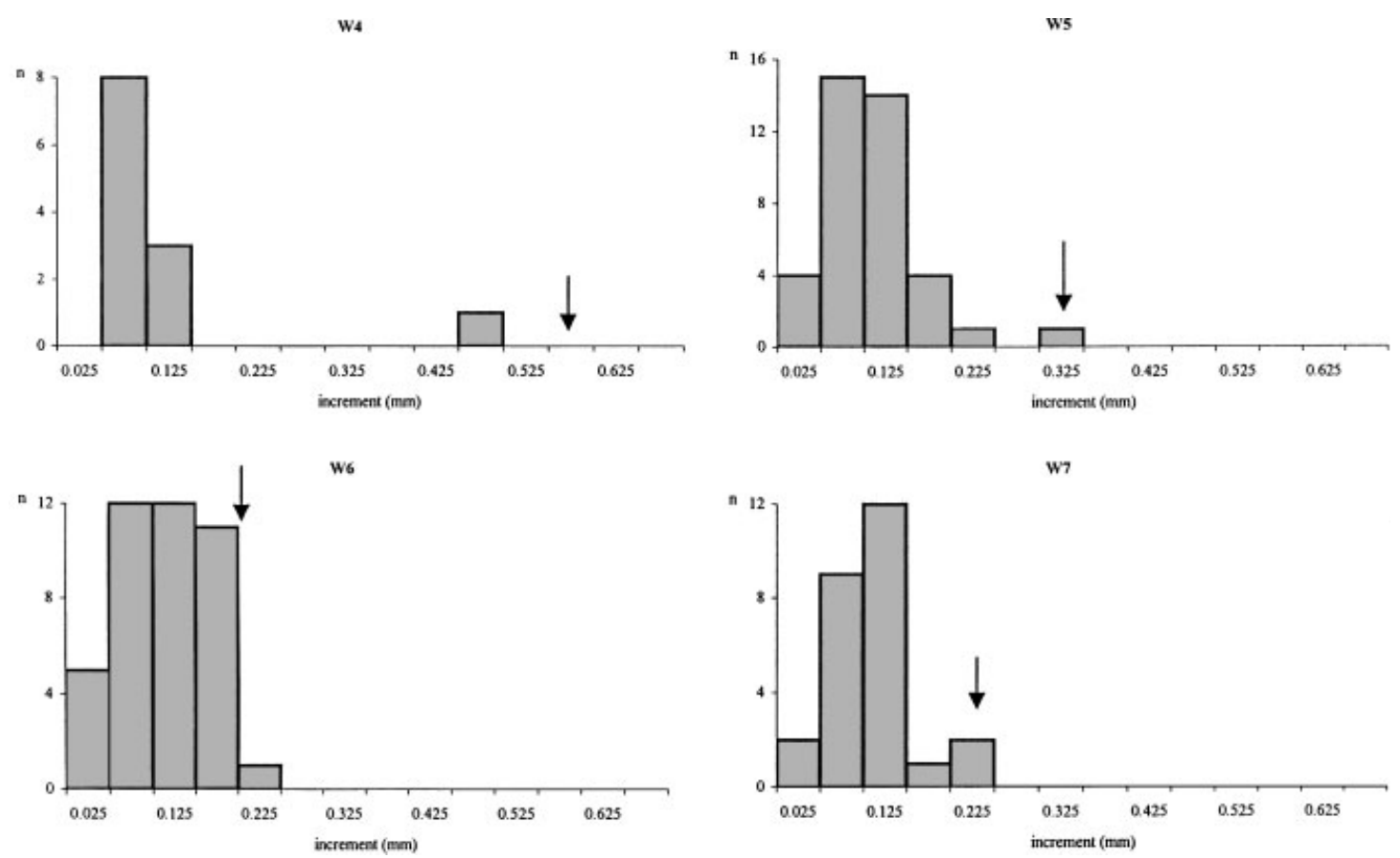

Figure 9. Distribution of the marginal increment (in $\mathrm{mm}$ ) of the $i$ th ring for plaice from the pit at Raversijde. The arrow indicates the expected mean width of the complete $i$ th rings of the same site. Upper left: fourth ring; upper right: fifth ring; bottom left sixth ring; bottom right seventh ring.

of the graphs. This indicates that the capture must have taken place at the beginning of the growth season. Single catches later within the year would gradually shift the peak towards the right part of the graph, so that ultimately the peak would coincide with the location of the arrow. However, since growth is not a linear process and slows down as the season continues, this shift will not happen at a constant pace and will therefore complicate the interpretation (or recognition of a single event later within the year).

Still better an approach is to compare the distribution of the marginal increments with that of the complete rings. For plaice from Raversijde, the frequency distribution of the fifth increment widths for complete rings are shown in Figure 10 plotted against the distribution for fifth rings that are marginal. The peak in the distribution of the complete increments corresponds to the arrow in Figure 9. As in Figure 9, it is obvious that plaice from the pit (Figure 10, upper panel) were captured at the beginning of the growth season, since the widths of the marginal increments are in the left part of the graph. Similarly,

Copyright (C) 2004 John Wiley \& Sons, Ltd. single catches later within the year should be indicated by a unimodal distribution more towards the right of the graph. However, it is again conceivable that such later single catches will be more difficult to place, since the growth slows down later in the growing season, as already explained above. When the marginal increments of all the other contexts at Raversijde are considered (Figure 10, lower panel), it appears that the major fishing season was also early in the season, as in the single depositional event, but that it continued for a longer period. From the Raversijde examples it is clear that a distinction can be made between single catches and assemblages that were fished over a longer period.

\section{Haddock}

The method outlined above has also been applied to haddock otoliths from Raversijde. Figure 11 shows the widths of their fourth marginal increments and compares them to the widths of complete fourth rings of individuals from the 

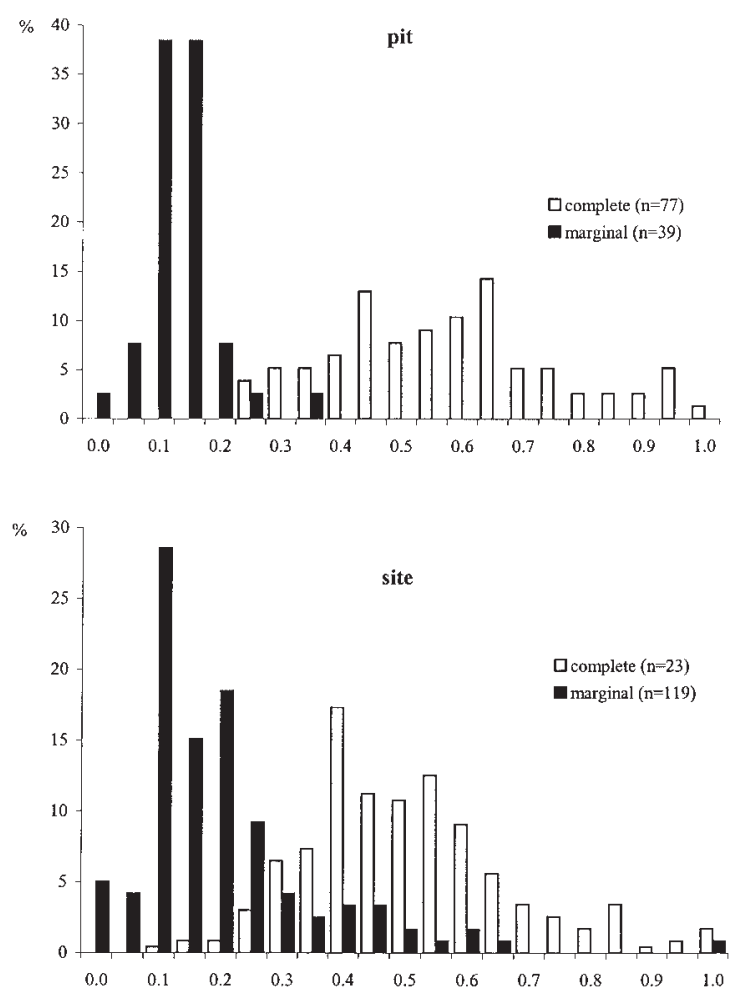

Figure 10. Frequency distribution of the width of the fifth increment (in $\mathrm{mm}$ ) for complete rings and for marginal increment of plaice from Raversijde for the pit (upper panel), and for the rest of the site (lower panel).

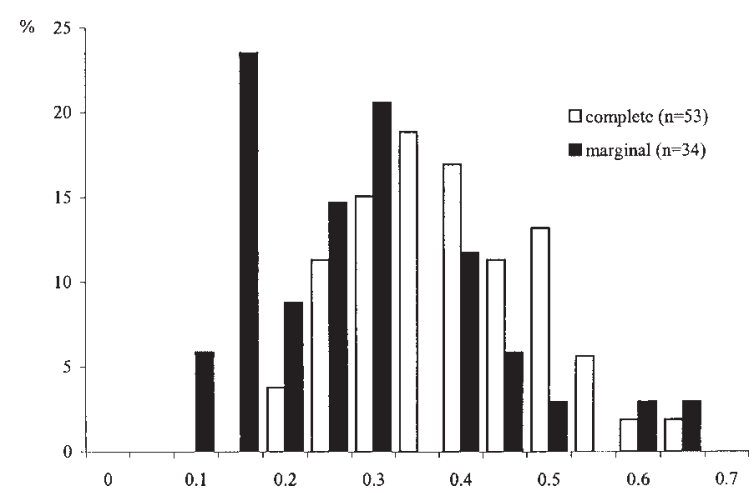

Figure 11. Frequency distribution of the width of the fourth increment (in $\mathrm{mm}$ ) for complete rings and for marginal increment of haddock from Raversijde.

same site. The position of the marginal increments' distribution differs completely from that observed in plaice. The distribution of the marginal increments coincides more-or-less with the one of the complete rings, meaning that the majority of haddock were captured when their growth was slow or non-existent. It is clear that the seasonality estimation obtained for haddock is at first sight less precise than the one for plaice. This is due to factors inherent to fish growth: after a period of fast growth (which starts in the warmer months with deposition of opaque material), growth slows down and hyaline material is deposited at a rather slow rate. Eventually, there is a growth stop. This means that in the case of the North Sea haddock, the fast growth will already result in a rather wide increment that can attain a thickness equalling or approaching the expected width of the full increment. In terms of seasonality estimation, this means that such otoliths with a broad marginal increment can be derived from fish that were still growing (but towards the end of their growth season) or from animals that were in a period of growth cessation. This period can cover more than half a year (from October to May according to the data from Figure 6). The graph in Figure 11 also shows a peak of narrow, marginal increments that corresponds to haddock that had just started their new growth. For those specimens it is obvious that the capture took place within a rather short period, although it is impossible to find out when this was exactly because haddock no longer live in the southern North Sea.

From the foregoing, it is clear that a precise seasonality estimate, using objective criteria, cannot be given for the specimens with a broad marginal increment. It is only when circumstantial evidence is used that the reconstructed fishing season can be narrowed down. We know that haddock otoliths from Raversijde do not represent material from a single depositional event, but if we refer to historical information describing haddock fishing as a winter activity, followed by a plaice season in spring (Egmond, 1997), then it is unlikely that the fishing season for haddock would have lasted over 6 months. Two main fisheries are indicated for haddock: one in the spawning period (February to May, with a peak in March and April), mainly in the northern North Sea, and a later fishery between September and October, when haddock were found feeding on central areas of the North Sea (Parrish, 1956; Quéro, 1997). However, there is obviously no information for the southern North Sea since the 
species no longer occurs here. The combination of the edge type data (Table 4) and the increment widths (Figure 11) suggests that haddock were captured over a period of only a few months maximum. The narrow marginal increments in Figure 11 correspond to the specimens indicated as 'O-' in Table 4, and it is conceivable that the otoliths with the broad marginal rings in Figure 11 (i.e. the specimens with a hyaline edge, and the $\mathrm{H} / \mathrm{O}$ category from Table 4) correspond to fish captured just before their new growth season was going to start. This would mean that the assemblage of Raversijde consists mainly of haddock fished rather late within the winter season and into the spring or early summer period, when the new growth started.

\section{Discussion}

\section{General implications}

The analysis of modern otoliths from fish with a known capture date has shown that there are severe shortcomings to the use of growth increments in the establishment of seasonality. Observing the frequencies of hyaline and opaque edges proves to be too crude to allow any precise interpretation. Moreover, it appears that the timing of the transition of one type to another is variable according to region. In addition there is interannual variation, and changes in edge type are also dependent on the age groups considered. Finally, the timing of the transition from one edge type to the other is only known for modern populations and it is not sure that these can provide useful reference data in all cases (see further).

To obtain more precision in the seasonality determination, the width of the marginal increment must be taken into account. Modern samples, such as the ones available for this study, allow the construction of a growth curve that documents the monthly increase in width of a given ring. The same drawbacks mentioned above (regional, interannual and age-related variation) apply here as well. Although the constructed curves show a clear average increase of the absolute increment width during the growth season, it appears that the individual variation within each monthly sample is huge. This pre-

Copyright (C) 2004 John Wiley \& Sons, Ltd. cludes the use of the width of a single archaeological otolith for the prediction of season of capture of the corresponding fish. Also the use of the mean width obtained from a large sample of archaeological otoliths, even when representing a single depositional event, cannot yield an accurate seasonality estimate because of the large variation around the mean.

An alternative way to approach the problem is to express the observed marginal width as a measure of the expected width, and thereby using reference information from the archaeological material itself. Monks \& Johnston (1993), in their methodological study on incremental analysis, concluded that in many cases good results can be obtained by supposing that the expected width equals the width of the preceding ring, but in the case of the fish studied here, a very poor relationship was found between the widths of two consecutive rings. As an alternative, this study proposes to quantify the marginal growth by comparing the size distribution of the marginal increment to the distribution of the widths of full-grown rings from the same rank (same year of life). This means that the analysed rings are the same age, but not necessarily all the fish. The advantage of this approach is that the effect of regional variation is ruled out, assuming that the archaeological sample investigated does not reflect catches from many different fishing grounds. Of course, interannual differences in growth can still play a role, but they will have a less prominent effect when the distribution of both complete and marginal rings are calculated on the basis of specimens representing different calendar years.

Applying the method proposed to an isolated, single otolith is not recommended, but in the case of assemblages representing a single catch, or even of larger assemblages representing multiple deposits, useful results can sometimes be obtained. However, in any case, sample sizes need to be sufficiently large to obtain meaningful distributions. The distribution of the fully-grown rings is wide and reflects the large variation also observed in the modern otoliths. Moreover, depending on where the distribution of marginal increments falls with respect to the complete ones of the same rank, the seasonality estimation will be more or less accurate. When the marginal rings are narrow,

Int. J. Osteoarchaeol. 14: 457-474 (2004) 
and only the tail of the upper part of the distribution overlaps with the lower end of the distribution of the complete rings, the conclusion can be drawn that the fish assemblage corresponds to a catch at the very beginning of the new growth season. However, within the growing period the marginal increment distribution will soon start to overlap with that of the complete rings. The growth rate is high at the beginning of the new growth season, but soon it gradually slows down. The result is that, except for the initial part of the fast growth season, the overlap of the two distributions will be such that it becomes impossible to decide where in time the marginal growth needs to be placed. Despite the apparently large sample size of the modern otoliths available, it appeared that the material was insufficient to plot significant distributions documenting the gradual monthly shift, a pattern already illustrated by the large variation in Figure 7.

All this means that extensive modern samples are needed to document the present-day growth characteristics of the species studied archaeologically. Even then there remains a degree of uncertainty, as fish growth may have been different in the past due to different predation pressure or different climatic conditions. In certain cases, it is not even possible to study the present-day growth patterns of species from a given region because their distributions have changed and they no longer occur on former fishing grounds near studied sites. Finally, there may always remain a fundamental problem with the comparison between recent and archaeological sets of otoliths because both samples may have been collected in different ways. The modern specimens come from fish that were caught at sea using modern fishing technology while the archaeological material derives from catches carried out in a more traditional way. It is thus conceivable that the recent material represents a more complete, or more random, sample from the populations than is the case for the archaeological material.

\section{Implications for Raversijde}

The plaice and haddock otoliths from Raversijde were grouped into three large assemblages: 119

Copyright (C) 2004 John Wiley \& Sons, Ltd. plaice otoliths corresponding to a single catch, 279 plaice specimens from various other contexts, and 202 haddock otoliths also representing multiple deposits. The advantage of working with this material is that it is abundant and that the Raversijde material derives from part of a fishermen's village only occupied during the 15 th century. The available otolith material from other archaeological sites in Flanders (cf. Van Neer et al., 2002: Table 1) is less abundant, dating is less precise and, because they are derived from consumer sites, the material is likely to be less homogenous as far as the geographical origin is concerned. It is fortunate that both plaice and haddock otoliths from Raversijde are so abundant, since the historical sources (Egmond, 1997: 118-119) indicate when their fishing took place in the 16th century in the southern North Sea: plaice fishing started early February when the landings of haddock decreased. Around March, vast quantities of plaice occurred inshore and their exploitation lasted for 2 or 3 months. Against this background and also taking into account present-day ecological data, an evaluation of the increment data obtained is facilitated.

The distribution of the marginal increments widths of plaice otoliths representing a single depositional event (Figure 10, upper panel) clearly shows that we are dealing with a catch that took place when the new growth season had just started. At the beginning of the growth season plaice resume feeding with a diet dominated by molluscs (Todd, 1914). The context with the plaice remains under study yielded large numbers of Donax vittatus shells, representing stomach contents of the fish (Van Neer \& Pieters, 1997). This also supports the hypothesis that the fish were captured shortly after the start of feeding in the spring. The historical scenario is corroborated by the evidence from the otolith analyses described above, pointing towards plaice fishing in spring, except for the ratio of hyaline versus opaque edges from this single catch which indicates fishing in summer. However, the reasons for this aberrant estimation have already been mentioned and include the fact that only modern reference data can be used for the $\mathrm{H} / \mathrm{O}$ ratio whereas the marginal increment data were compared to full rings from the archaeological population itself.

Int. J. Osteoarchaeol. 14: 457-474 (2004) 
The assemblage of plaice otoliths collected at several other locations of Raversijde (Figure 10, lower panel) produces a marginal increment width distribution that is only slightly different from the one seen for the single catch. It seems that plaice fishing at Raversijde has always been an activity that took place at the beginning of the new growth season. A random sample of 13 plaice otoliths from this assemblage was used for oxygen isotope analysis. The results demonstrate that the fishing season was consistent in all specimens (Patterson, 2000; Patterson et al., in preparation). $\delta^{18} \mathrm{O}_{(\mathrm{CaCO})}$ values are at a seasonal maximum or are just beginning to decrease, indicating that these fish were captured in late winter/early spring, most likely in the month of March.

The interpretation of the increment distributions is less straightforward for the assemblage of haddock otoliths (Figure 11). The marginal increment distribution corresponds more-or-less with the distribution seen in fish that have terminated the growth of that particular ring, with the exception that there is a significant number of specimens that are clearly at the beginning of a new growth season. As already explained above, the otoliths with narrow outer bands represent fish that just started their new growth season, which in adult specimens, is after spawning. Nowadays haddock spawn in the northern North Sea mainly between March and April (Parrish, 1956; Quéro, 1997). The growth patterns of other gadoids from various parts of the North Sea (Knijn et al., 1993) suggest that the late medieval haddock that populated the southern North Sea must have started spawning earlier than the modern northern populations. However, it cannot be established exactly when this was.

It makes sense to consider the other individuals - with the fully-grown rings - as fish that were caught in the period just before those in which the new growth had started, but this cannot be proven using the increment data as such. This is a problem inherent to the use of growth rings: once a critical marginal width is reached, it is impossible to distinguish specimens that were caught towards the end of the growth season or the period of growth cessation. This period lasts approximately half a year, meaning that objective seasonality estimations cannot be performed on this basis. The same methodological problem had

Copyright (C) 2004 John Wiley \& Sons, Ltd. already been encountered during the analysis of growth rings in the pectoral spines of catfish (Van Neer et al., 1993). Oxygen isotope analyses of haddock otoliths from Raversijde will be performed in an attempt to narrow down the seasonality estimation in a more objective way.

\section{Conclusion}

It was believed at the beginning of this project that the large sample sizes of investigated archaeological otolith assemblages and their comparison with extensive modern otolith collections would enable the refinement of methods for seasonality analysis. Considerable criticisms of increment studies for archaeozoological purposes had been offered by Carlson (1988), which were countered, on a rather theoretical basis, by Desse \& Desse-Berset (1992). The present analyses, however, confirm the difficulties inherent to archaeozoological applications postulated by Carlson (1988). The conclusion from the foregoing analyses is that the chances of obtaining a good seasonality estimation depend on 1) the season of capture itself: when the major season of capture coincides with a period of rapid growth, especially the beginning of a new growth season, chances are high that this season can be determined, and 2) the amount of material and the type of context from which it is derived: single depositional events, or a rather short seasonal event that is repeated year after year, are likely to produce better results. Finally, circumstantial evidence is of course much welcomed, such as historical data on former fishing practices, as well as data on the feeding and spawning behaviour and related migrations resulting in seasonal changes of abundance and accessibility.

\section{Acknowledgements}

The authors wish to thank Marnix Pieters (Institute for the Archaeological Heritage of the Flemish Community, IAP) for providing the Raversijde otoliths and Luc Muylaert (IAP) for assisting with the retrieval of the otoliths from the sieved residues. Dr Dirk Nolf (Royal Belgian Institute of Natural Sciences) assisted with the 
identification of the otoliths, and Richard Ayers (CEFAS), Piet van Leeuwen (Netherlands Institute for Fisheries Research), Daphne Stalpaert (Royal Museum for Central Africa, KMMA) and Peter De Smedt (KMMA) are thanked for their help with otolith reading and measuring. Sheila Hamilton-Dyer (Southampton) kindly did the linguistic corrections. The research was made possible thanks to the support of the European Commission (through a grant under the FAIR Programme) and of national research programmes (Netherlands Institute for Fisheries Research RIVO DLO-Programme 324: Aquatic Ecosystems and Fisheries; Centre for Estuarine Fisheries and Aquaculture Research CEFAS Programme, Department of Sea Fisheries Programme). The contribution of Wim Van Neer to this paper also presents research results of the Interuniversity Poles of Attraction Programme Belgian Federal Science Policy Office.

\section{References}

Alhoussaini M, Pitcher TJ. 1988. The relation between daily rings, body growth and environmental factors in plaice, Pleuronectes platessa L., juvenile otoliths. Journal of Fish Biology 33: 409-418.

Beckman DW, Wilson CA. 1995. Seasonal timing of opaque zone formation in fish otoliths. In Recent Developments in Fish Otolith Research, Secor DH, Dean JM, Campana S (eds). University of South Carolina Press: Columbia; 27-44.

Bedford BC. 1983. A method for preparing sections of large numbers of otoliths embedded in black polyester resin. Journal du Conseil International pour l'Exploration de la Mer 41: 4-12.

Bourque BJ, Morris K, Spiess A. 1978. Determining the season of death of mammal teeth from archeological sites: a new sectioning technique. Science 199: 530-531.

Brewer D. 1987. Seasonality in the prehistoric Faiyum based on the incremental growth structures of the Nile catfish (Pisces: Clarias). Journal of Archaeological Science 14: 459-472.

Brothers EB. 1981. What can otolith microstructure tell us about daily and sub-daily events in the early life history of fish? Rapports et Procès-Verbaux des Réunions/Conseil International pour l'Exploration de la Mer 178: 393-394.

Burke A, Castanet J. 1995. Histological observations of cementum growth in horse teeth and their application to archaeology. Journal of Archaeological Science 22: 479-493.

Carlson C. 1988. An evaluation of fish growth annuli for the determination of seasonality in archaeological sites. In Recent Developments in Environmental Analysis in Old and New World Archaeology, Webb E (ed.). (BAR International Series 416). British Archaeological Reports: Oxford; 67-78.

Claessen C. 1993. Problems and choices in shell seasonality studies and their impact on results. Archaeozoologia 5(2): 55-76.

Desse J. 1983. Les restes de poissons dans les fosses omaliennes. In Les Fouilles de la Place Saint-Lambert à Liège, Ministère de la Communauté Française, Administration du Patrimoine Culturel (ed.). Liège; 22-23.

Desse J, Desse-Berset N. 1992. Age et saison de mort des poissons: applications à l'archéologie. In Tissus Durs et Age Individuel des Vertebrés, Baglinière J-L, Castanet J, Conand F, Meunier FJ (eds). ORSTOM: Paris; 341-353.

Desse J, Desse-Berset N. 1993. Les poissons. In Les babitats du lac de Paladru (Isère) dans leur environnement: La formation d'un terroir au Xe siècle, Colardelle M, Verdel E (eds). Documents d'Archéologie Française 40: 116-120.

Egmond F. 1997. Een bekende Scheveninger: Adriaen Coenen en zijn Visboeck van 1578. Centrum voor Familiegeschiedenis van Scheveningen: Den Haag.

Ervynck A, Van Neer W, Pieters M. in press. How the North was won (and lost again). Historical and archaeological data on the exploitation of the North Atlantic by the Flemish fishery. In Atlantic Connections and Adaptations: Economies, Environments and Subsistence in Lands bordering the North Atlantic, Housley RA, Coles GM (eds). Oxbow: Oxford.

Gaillard JM, Testud A-M. 1980. Comparative study of Quaternary and present-day lagoon populations of Cardium glaucum (syn. Cerastoderma glaucum (Bruguière)), Mollusca, Bivalvia. In The Geology of Libya, Volume III, Salem MJ, Busrewil MT (eds). Academic Press: London; 810-814.

Habermehl K-H. 1985. Altersbestimmung bei Wild-und Pelztieren. Verlag Paul Parey: Hamburg/Berlin.

Hales LS, Reitz EJ. 1992. Historical changes in age and growth of Atlantic croaker, Micropogonias undulatus (Perciformes: Sciaenidae). Journal of Archaeological Science 19: 73-99.

Ham LC, Irvine M. 1975. Techniques for determining seasonality of shell middens from marine mollusc remains. Syesis 8: 363-373.

Higham TFG, Horn PL. 2000. Seasonal dating using fish otoliths: results from the Shag River Mouth Site, New Zealand. Journal of Archaeological Science 27: 439-448. 
Keiss RE. 1969. Comparison of eruption-wear patterns and cementum annuli as age criteria in elk. Journal of Wildlife Management 33: 175-180.

Klevezal GA, Kleinenberg SE. 1967. Age Determination of Mammals from Annual Layers in Teeth and Bones. Akademiya Nauk SSSR, Institut Morpologii Zhivotnyich Im. A. N. Severtsova, Izdatal'stvo 'Nauka' Moscow. Jerusalem: Israel Program for Scientific Translations, 1969.

Klevezal GA, Kallar Sallas AV, Kirpichev SP. 1972. Determination of age in birds by layers in the periosteal zone. Zoologicheskii Zhurnal 51: 17261730.

Knijn RJ, Boon TW, Heessen HJL, Hislop JRG. 1993. Atlas of North Sea Fishes. ICES Cooperative Research Reports 194. ICES: Copenhagen.

Koike H. 1975. The use of daily and annual growth lines of the clam Meretrix lusoria in estimating seasons of Jomon Period shell gathering. In Quaternary Studies, Suggate RP, Cresswell MM (eds). Wellington: The Royal Society of New Zealand; 189-193.

Laws RM. 1952. A new method of age determination for mammals. Nature 169: 972-973.

Laws RM. 1968. Dentition and ageing of the hippopotamus. East African Wildlife Journal 6: 19-52.

Le Cren ED. 1947. The determination of age and growth of the perch (Perca fluviatilis) from the opercular bone. Journal of Animal Ecology 16: 188-204.

Lieberman DE. 1994. The biological basis for seasonal increments in dental cementum and their application to archaeological research. Journal of Archaeological Science 21 : 525-539.

Lieberman DE, Meadow RH. 1992. The biology of cementum increments (with an archaeological application). Mammal Review 22: 57-77.

Lubinski PM. 2001. Estimating age and season of death of Pronghorn Antelope (Antilocapra americana Ord) by means of tooth eruption and wear. International Journal of Osteoarchaeology 11 : 218-230.

Lubinski PM, O'Brien CJ. 2001. Observations on seasonality and mortality from a recent catastrophic death assemblage. Journal of Archaeological Science 28: 833-842.

Marzolf RC. 1955. Use of pectoral spines and vertebrae for determining age and growth of the channel catfish. Journal of Wildife Management 19: 243-249.

Matschke GH. 1967. Ageing European wild hogs by dentition. Journal of Wildlife Management 31: 109-113.

McKinley V, Burke A. 2000. A new control sample for season of death estimates for Equus caballus from dental thin-sections. Archaeozoologia 11 : 33-42.

Milner N. 2001. At the cutting edge: using thin sectioning to determine season of death of the
European Oyster, Ostrea edulis. Journal of Archaeological Science 28: 861-873.

Monks G, Johnston R. 1993. Estimating season of death from growth increment data: a critical review. Archaeozoologia 5(2): 17-40.

Morris PA. 1972. A review of mammalian age determination methods. Mammal Review 2: 69-104.

Mosegaard H, Svedang H, Taberman K. 1988. Uncoupling of somatic and otolith growth rates in Arctic char (Salvelinus alpinus) as an effect of differences in temperature response. Canadian Journal of Fisheries and Aduatic Sciences 45: 1514-1524.

Mosegaard H, Morales-Nin B, Weidman C, Geffen A, Arneri E, Millner R, Panfili J, Folkvord A. 1998. Otolith thin-section preparation: some problems and new developments. In Otolith Preparation and Analysis: Proceedings of a Workshop beld at the University of Bergen, Norway, June 18-20, 1998, Wright PJ (ed.). Marine Laboratory Aberdeen: Aberdeen; $10-19$.

Noe-Nygaard N. 1983. The importance of aquatic resources to Mesolithic man at inland sites in Denmark. In Animals and Arcbaeology: 2. Shell Middens, Fish and Birds, Grigson C, Clutton-Brock J (eds). (BAR International Series 183). British Archaeological Reports: Oxford, 125-142.

Parrish BB. 1956. The cod, haddock and hake. In Sea Fisheries, their Investigation in the United Kingdom, Graham M (ed.). Edward Arnold: London; 251-331.

Patterson W. 2000. High resolution stable isotope analyses. In Changes in Growth of Demersal Fish in the North Sea in Medieval and Recent Time Periods, with Particular Reference to the Effect of the Industrialisation of the Fisheries, Bolle L, Rijnsdorp AD (eds). Final Report EU-Contract FAIR CT97-3462: IJmuiden; 53-57.

Pieters M. 1997. Raversijde: a late medieval fishermen's village along the Flemish coast (Belgium, province of West-Flanders, municipality of Ostend). In Rural settlements in Medieval Europe: Papers of the 'Medieval Europe Brugge 1997' Conference, Volume 6, De Boe G, Verhaeghe F (eds). (IAP Rapporten 6). Institute for the Archaeological Heritage of the Flemish Community: Zellik, 169-177.

Pieters M, Ervynck A, Van Neer W, Verhaeghe F. 1994. Raversijde: een 15 de eeuwse kuil, een lens met platvisresten, en de betekenis voor de studie van de site en haar bewoners. Archeologie in Vlaanderen 4: 253-277.

Pieters M, Bouchet F, Cooremans B, Desender K, Ervynck A, Van Neer W. 1996. Granaatappels, een zeeëngel en rugstreeppadden: Een greep uit de inhoud van een bakstenen beerput uit het 15de-eeuwse Raversijde (stad Oostende, prov. 
West-Vlaanderen). Archeologie in Vlaanderen 5: 193224.

Quéro J-C. 1997. Les Poissons de Mer des Pêches Françaises. Delachaux et Niestlé: Lausanne/Paris.

Rijnsdorp AD, van Leeuwen PI, Visser TAM. 1990. On the validity and precision of back-calculation of growth from otoliths of the plaice, Pleuronectes platessa L. Fisheries Research 9: 97-117.

Rijnsdorp AD, van Leeuwen PI, Daan N, Heessen HJL. 1996. Changes in abundance of demersal fish species in the North Sea between 1906-1909 and 1990-1995. ICES Journal of Marine Science 53: 10541062.

Smith HA. 1983. Determination of seasonality in archaeological sites through examination of fish otoliths: a case study. Journal of Field Archaeology 10: 498-500.

Stallibrass S. 1982. The use of cement layers for absolute ageing of mammalian teeth: a selective review of the literature, with suggestions for further studies and alternative applications. In Ageing and Sexing Animal Bones from Archaeological Sites, Wilson B, Grigson C, Payne S (eds). (BAR International Series 109). British Archaeological Reports: Oxford; 109-126.

Stone WB, Morris K. 1981. Aging male ring-necked pheasants by bone histology. New York Fish and Game Journal 28: 223-229.

Todd RA. 1915. The food of plaice. Fishery Investigations, series II. 2(3): 1-31.

Van Neer W. 1993. Limits of incremental growth in seasonality studies: the example of the clariid pectoral spines from the byzantino-islamic site of
Apamea (Syria, 6th-7th century A.D.). International Journal of Osteoarchaeology 3: 119-127.

Van Neer W, Pieters M. 1997. Evidence for processing of flatfish at Raversijde, a late medieval coastal site in Belgium. Anthropozoologica 25/26: 571-578.

Van Neer W, Augustynen S, Linkowski T. 1993. Daily growth increments on fish otoliths as seasonality indicators on archaeological sites: the tilapia from late Palaeolithic Makhadma in Egypt. International Journal of Osteoarchaeology 3: 241-248.

Van Neer W, Lougas L, Rijnsdorp AD. 1999. Reconstructing age distribution, season of capture and growth rate of fish from archaeological sites based on otoliths and vertebrae. International Journal of Osteoarchaeology 9: 116-130.

Van Neer W, Ervynck A, Bolle LJ, Millner RS, Rijnsdorp AD. 2002. Fish otoliths and their relevance to archaeology: an analysis of medieval, post-medieval and recent material of plaice, cod and haddock from the North Sea. Environmental Archaeology 7: 65-81.

Watson JE. 1964. Determining the age of young herring from their otoliths. Transactions of the American Fisheries Society 93: 11-20.

Weinand DC. 2000. Seasonality examination of white-tailed deer increment structures from coastal Georgia, USA. Archaeozoologia 11: 65-78.

Whittaker WE, Enloe JG. 2000. Bison dentition studies revisited: resolving ambiguity between archaeological and modern control samples. Archaeozoologia 11: 113-120. 